\title{
Re: Hasegawa EM, Fuller R, Chammas MC, de Mello FM, Goldenstein-Schainberg C: Increased prevalence of simple renal cysts in patients with gout. Rheumatol Int, DOI 10.1007/s00296- 012-2380-x
}

\author{
Urmila Dhakad · Bhupendra Pal Singh • \\ Rahul Yadav
}

Received: 6 May 2012/ Accepted: 20 January 2013/Published online: 3 February 2013

(c) Springer-Verlag Berlin Heidelberg 2013

We appreciate the authors for observing the increased association of simple renal cysts in gout patients [1]. This being a quite interesting study, however, some points need further elaboration as far as results of the study are concerned.

Authors have found no association of renal impairment with the presence of simple renal cyst in gout patients. They have chosen a cutoff limit of $60 \mathrm{ml} / \mathrm{min} / 1.72 \mathrm{~m}^{2}$ body surface area (BSA) for impaired renal function. As it is known that any degree of impaired renal function facilitates simple cysts in kidneys, we believe that the cutoff limit of $60 \mathrm{ml} / \mathrm{min} / 1.72 \mathrm{~m}^{2}$ BSA is quite low to categorize patients into two different groups according to renal function. If chosen a GFR of $<90 \mathrm{ml} / \mathrm{min} / 1.72 \mathrm{~m}^{2}$ BSA, the results would have been different. The acquired cystic renal disease may begin early in the course of the renal disease [2], so the point of earliest renal impairment may be more important rather than obvious renal impairment or duration of gout.

Authors have chosen controls from age-matched healthy donors and found the incidence of simple renal cysts higher in gout patients. Healthy age-matched donors are usually free of associated comorbidities (like hypertension, renal impairment) which facilitate simple renal cysts formation in kidneys. If controls would have been age-matched general population or age-matched cohorts coming to routine health check up, the incidence of simple renal cysts probably would have been more in control group.

Authors have found negative correlation of simple renal cysts with nephrolithiasis in gout patients. Before inferring this negative association, it would have been ideal if authors have ruled out that other factors predisposing renal stone formation (like daily fluid intake/urine output, protein intake, serum /urine uric acid excretion, serum/24 h urinary calcium, drugs like any diuretics) were not different in those without cysts compared to those with cysts. Without appropriate metabolic workup for susceptibility of stones (of uric acid as well as other types) in gout which is a metabolic disease, this negative correlation of nephrolithiasis with cysts should be taken as a preliminary and simplistic conclusion only.

\section{References}

1. Hasegawa EM, Fuller R, Chammas MC, de Mello FM, Goldenstein-Schainberg $\mathrm{C}$ Increased prevalence of simple renal cysts in patients with gout. Rheumatol Int. doi:10.1007/s00296-012-2380-x

2. Al-Said J, Brumback MA, Moghazi S, Baumgarten DA, O'Neill WC (2004) Reduced renal function in patients with simple renal cysts. Kidney Int 65(6):2303-2308
U. Dhakad ( $\square)$

Department of Rheumatology, Chhatrapati Shahuji Maharaj

Medical University, Lucknow, Uttar Pradesh, India

e-mail: drurmiladhakad@gmail.com

B. P. Singh $\cdot$ R. Yadav

Department of Urology, Chhatrapati Shahuji Maharaj Medical

University, Lucknow, Uttar Pradesh, India 